\title{
Polyuria: A Pathophysiologic Approach
}

By Kirstie Lithgow, BSc, MD and Bernard Corenblum MD, FRCPC

\begin{abstract}
About the Authors
Kirstie Lithgow and Bernard Corenblum are with the Department of Medicine, Cumming School of Medicine, University of Calgary, Calgary, AB. Corresponding author: kclithgo@ucalgary.ca
\end{abstract}

A 22-year-old man presented with a 3-week history of increased thirst, polydipsia, and polyuria. He described consuming large volumes of water and waking up multiple times throughout the night to drink and urinate. He also endorsed symptoms of fatigue and frequent headaches. Prior to this, he had been well. There was no history of diuretic use, lithium use, or renal disease. There was no prior head trauma, cranial irradiation, or intracranial pathology. He denied consumption of nutritional or protein supplements. Clinical exam revealed a well appearing young man with normal heart rate and blood pressure. Visual fields and general neurologic exam were grossly normal.

Baselines investigations revealed serum sodium ranging from 141-142 $\mathrm{mmol} / \mathrm{L}$ (reference range 133-145 mmol/L), creatinine $92 \mathrm{umol} / \mathrm{L}(50-120 \mathrm{umol} / \mathrm{L})$, random glucose 5.4 $\mathrm{mmol} / \mathrm{L}$ (3.3-11.0 mmol/L), potassium $4.0(3.3-5.1 \mathrm{mmol} / \mathrm{L})$ and ionized calcium $1.25 \mathrm{mmol} / \mathrm{L}$ (1.15-1.35 mmol/L).

A 24-hour urine collection was arranged, and returned a urine volume of 5.6L (normal less than 3 litres/24 hours). Further investigations revealed a serum sodium of $142 \mathrm{mmol} / \mathrm{L}$, serum osmolality $306 \mathrm{mmol} / \mathrm{kg}$ (280-300 mmol/kg), and urine osmolality of $102 \mathrm{mmol} / \mathrm{kg}$ (50-1200 mmol/ $\mathrm{kg})$. AM cortisol was $372 \mathrm{nmol} / \mathrm{L}(200-690 \mathrm{nmol} / \mathrm{L})$.

These results demonstrated inability to concentrate the urine, despite the physiologic stimulus of hyperosmolarity. Based on this, a presumptive diagnosis of diabetes insipidus was made. The patient was instructed to drink as much as he needed to satiate his thirst, and to avoid fluid restriction. The patient was started on DDAVP intranasal spray, which provided immediate relief from his symptoms. Magnetic resonance imaging of the brain revealed an unremarkable pituitary gland with abnormal thickening of the pituitary stalk and loss of the posterior pituitary bright spot. This confirmed the diagnosis of central diabetes insipidus, presumed secondary to infiltrative disease affecting the pituitary stalk.

\section{Introduction}

Polyuria is defined as inappropriately high urine output relative to effective arterial blood volume and serum sodium. In adults, polyuria can be objectively quantified as urine output in excess of 3-3.5 L per day with a low urine osmolality $(<300 \mathrm{mmol} / \mathrm{kg}){ }^{2}$

Daily urine output is dependent on 2 major factors. The first is the amount of daily solute excretion, and the second is the urine concentrating capability of the nephron. ${ }^{3}$ Disturbances in either of these factors can occur by many different mechanisms, and can lead to a diuresis. This diuresis can be driven either by solute (solute diuresis), water (water diuresis) or a combination of these processes. ${ }^{4} \mathrm{~A}$ diagnostic algorithm for polyuria is outlined in Figure 1.

\section{Solute Diuresis}

Daily solute intake varies between individuals, but typically averages about $10 \mathrm{mmol} / \mathrm{kg}$ or $500-800 \mathrm{mmol} / \mathrm{day}^{2,3}$ Solute diuresis is the result of a higher solute load that exceeds the usual solute excretion. ${ }^{4}$ Higher solute loads can be a consequence of either increased solute intake or increased solute generation through metabolism. High solute intake can occur from intravenous fluids, enteral or parental nutrition, and any other sources of exogenous protein, glucose, bicarbonate, or sugar alcohols. ${ }^{2,4}$ Metabolic processes leading to increased solute generation include hyperglycemia and azotemia., ${ }^{2,4}$ Increased solute excretion drives urine output in a linear fashion. ${ }^{3}$ Furthermore, solute diuresis impairs the ability of the kidney to concentrate urine. Typically, in a pure solute diuresis, urine concentration is between 300 and $500 \mathrm{mmol} / \mathrm{kg}^{2,4}$ The specific cause of solute diuresis can be further delineated with estimation of the urine electrolyte solute over 24 hours: 2 (urine $[\mathrm{Na}]+$ urine $[\mathrm{K}]$ ) $\times 24$ hours. ${ }^{4}$ Values greater than $600 \mathrm{mmol} /$ day suggest electrolytes are the solutes driving the diuresis, while values less than $600 \mathrm{mmol} /$ day imply that the diuresis is due to a non-electrolyte solute, typically glucose or urea. 


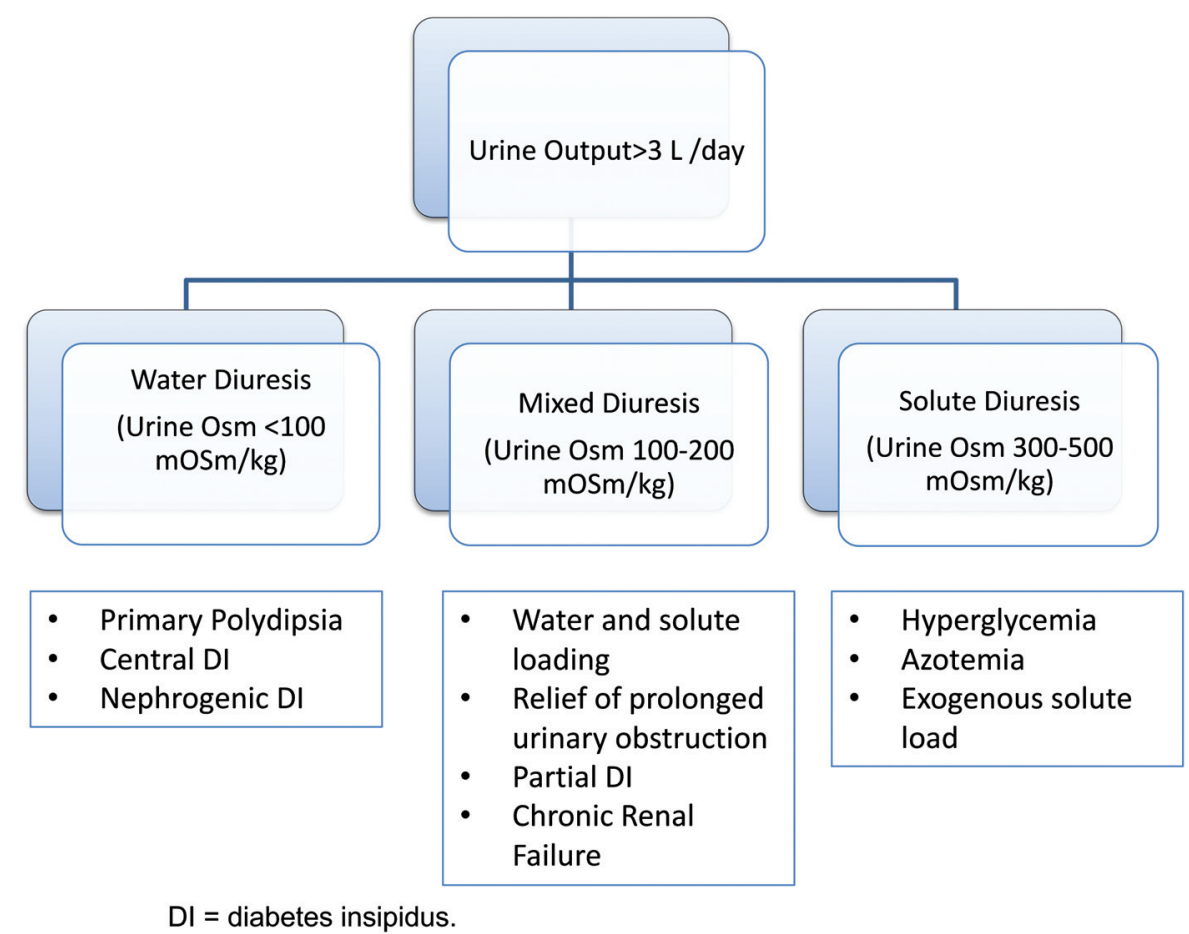

Figure 1. Diagnostic approach to polyuria

\section{Water Diuresis}

Water diuresis can occur due to excessive amounts of free water consumption (primary polydipsia) or impaired secretion or response to $\mathrm{ADH}$ (diabetes insipidus). In both cases, urine osmolality should be less than $100 \mathrm{mmol} / \mathrm{kg}^{2}$ Primary polydipsia is characterized by excessive water consumption. This can be a result of compulsive water drinking (often observed in psychiatric disorders) or a defect in the thirst centre of the hypothalamus due to an infiltrative disease process. ${ }^{5,6}$

The osmotic threshold for ADH release occurs at 280-290 $\mathrm{mmol} / \mathrm{kg}$. Failure to maximally concentrate the urine (1000-1200 $\mathrm{mmol} / \mathrm{kg}$ in healthy kidneys) when serum osmolality rises above the osmotic threshold suggest diabetes insipidus. ${ }^{3}$ Diabetes insipidus (DI) can result from either insufficient ADH secretion from the posterior pituitary (central DI) or ADH resistance (nephrogenic DI). ${ }^{1}$

Central DI can be caused by both congenital and acquired conditions known to affect the hypothalamic-neurohypophyseal system $^{7,8}$ (Table 1). Polyuria occurs when $80 \%$ or more of the $\mathrm{ADH}$ secreting neurons are damaged ${ }^{7}$. Metastatic disease has a predilection for the posterior pituitary, as its blood supply is derived from the systemic circulation, in contrast to the anterior pituitary which is supplied by the hypophyseal portal system. ${ }^{9}$ Rapid onset of polydipsia and polyuria in a patient older than
50 years of age should therefore raise immediate suspicion for metastatic disease. ${ }^{9}$ Treatment of adrenal insufficiency may "unmask" or exacerbate central DI, as normalization of blood pressure following glucocorticoid replacement inhibits $\mathrm{ADH}$ release. $^{10}$

In the pregnant state, $\mathrm{ADH}$ degradation is increased due to placental production of vasopressinase. Any mechanism of hepatic dysfunction that occurs in pregnancy (pre-eclampsia, HELLP, acute fatty liver) will augment this normal physiology by reducing vasopressinase clearance, and can subsequently lead to transient DI ${ }^{11}$

In nephrogenic $\mathrm{DI}, \mathrm{ADH}$ is present but the kidneys are unable to respond appropriately. ${ }^{8}$ In normal physiology, $\mathrm{ADH}$ acts to concentrate the urine via activation of the vasopressin $\mathrm{V} 2$ receptor, which leads to insertion of aquaporin-2 water channels in the collecting duct. ${ }^{3,12}$ Nephrogenic DI can be primary (genetic) or secondary (acquired). Primary nephrogenic DI occurs as a result of genetic mutations affecting either the vasopressin 2 receptor or aquaporin-2 water channels; typically, such conditions present in infancy. ${ }^{12}$ Secondary nephrogenic DI can occur by a variety of mechanisms; the most common is chronic lithium administration. Lithium enters the principal cell in the collecting duct via epithelial sodium channels, and is thought to impair urinary concentrating ability via reduction in the number of principal cells and interference in signalling pathways involved 
in aquaporin. ${ }^{12,13}$ Hypercalcemia, hypokalemia, obstructive uropathy, and pregnancy can lead to transient nephrogenic DI. ${ }^{12,13}$ Hypercalcemia can lead to nephrogenic DI by causing a renal concentrating defect when calcium levels are persistently above $2.75 \mathrm{mmol} / \mathrm{L} .{ }^{14}$ Increased hydrostatic pressure from obstructive uropathy may lead to suppression of aquaporin-2 expression, resulting in transient nephrogenic DI. ${ }^{12}$ Nephrogenic DI can be caused by various renal diseases due to impairment of renal concentrating mechanisms, even before glomerular filtration rate is impaired. Polycystic kidney disease causes anatomic disruption of the medullary architecture. Polyuria in sickle cell disease results from a similar mechanism, as sickling in the vasa recta interferes with the countercurrent exchange mechanisms ${ }^{16}$. Infiltrative renal disease including amyloid and
Sjogren's syndrome impair renal tubular function due to amyloid deposition and lymphocytic infiltration. ${ }^{17,18}$

\section{Mixed Water-Solute Diuresis}

In some cases, polyuria can be caused by a combination of both mechanisms. The linear relationship between solute excretion and urine output described above is strongly influenced by $\mathrm{ADH}$. In the setting of a solute diuresis, absence or deficiency of $\mathrm{ADH}$ can augment the degree of polyuria quite dramatically. ${ }^{14,19}$ Clinical examples of mixed diuresis include concurrent loading of both water and solute, chronic renal failure or infiltrative renal disease, relief of prolonged urinary obstruction, and partial DI. ${ }^{2,4}$ Typically in such scenarios, urine osmolality ranges from 100-300 mmol/.kg. ${ }^{2}$
Table 1. Etiologies of Central Diabetes Insipidus

Tumours
Trauma

Infiltrative/autoimmune

Infiltrative/autoimmune

Congenital

\section{Conclusion}

Polyuria has a broad range of causes and can be a diagnostic challenge for clinicians. Understanding the pathophysiology that underpins the different mechanisms of polyuria is essential to appropriate workup, diagnosis, and treatment of this condition. If this is a complaint, the first step is to quantitate the 24-hour urine volume. We recommend referral to endocrinology when there is evidence of hypothalamic or pituitary disease, when a water deprivation test is required, or in cases where the diagnosis is unclear.

\section{Disclosure}

Funding sources: None. Conflicts of interest: None.
Pituitary adenoma (with suprasellar extension)

Craniopharyngioma

Germinoma

Metastatic disease

Closed head injury

Pituitary apoplexy

Post-surgical

Langerhan's cell histiocytosis

Lymphocytic hypophysitis

IGG4 related disease

Sarcoidosis

Immune checkpoint inhibitors

Familial Central Diabetes Insipidus

Wolfram syndrome

Septo-optic dysplasia

Congenital hypopituitarism 
8. Mahzari M, Liu D, Arnaout A, Lochnan H. Immune checkpoint inhibitor therapy associated hypophysitis. Clin Med Ins Endocrin Diabet 2015;8:21-8.

9. Hermet M, Delévaux I, Trouillier S, André M, Chazal J, Aumaître O. Diabète insipide révélateur de métastases hypophysaires : quatre observations et revue de la littérature. La Revue de Médecine Interne 2009;30(5):425-9.

10. Martin MM. Coexisting anterior pituitary and neurohypophyseal insufficiency: A syndrome with diagnostic implication. Arch Intern Med 1969;123(4):409-16.

11. Aleksandrov N, Audibert F, Bedard MJ, Mahone M, Goffinet F, Kadoch IJ. Gestational diabetes insipidus: a review of an underdiagnosed condition. J Obstet Gynaecol Can 2010;32(3):225-31.

12. Bockenhauer D, Bichet DG. Pathophysiology, diagnosis and management of nephrogenic diabetes insipidus. Nat Rev Nephrol 2015;11(10):576-88.

13. Grünfeld JP, Rossier BC. Lithium nephrotoxicity revisited. Nat Rev Nephrol 2009;5(5):270

14. Rose BD, Post TW. Clinical physiology of acid-base and electrolyte disorders. 5th ed. New York: McGraw-Hill, Medical Pub. Division; 2001, 754
15. Gabow PA, Kaehny WD, Johnson AM, Duley IT, Manco-Johnson M, Lezotte DC, et al. The clinical utility of renal concentrating capacity in polycystic kidney disease. Kidney Internat 35(2):675-80.

16. Hatch FE, Culbertson JW, Diggs LW. Nature of the renal concentrating defect in sickle cell disease. J Clin Invest 1967;46(3):336-45

17. Carone FA, Epstein FH. Nephrogenic diabetes insipidus caused by amyloid disease: Evidence in man of the role of the collecting ducts in concentrating urine. Am J Med 1960;29(3):539-44.

18. Shearn MA, Tu W-H. Nephrogenic diabetes insipidus and other defects of renal tubular function in Sjögren's syndrome. Am J Med 1965;39(2):312-8.

19. Rennke HG, Denker BM. Renal pathophysiology: the essentials. 4th ed. Philadelphia: Wolters Kluwer/Lippincott Williams \& Wilkins; 2014. Figure 3.7, effects of $\mathrm{ADH}$ and solute excretion on urine volume, 88 